\title{
CONCEITOS DE QUÍMICA DOS INGRESSANTES NOS CURSOS DE GRADUAÇÃO DO INSTITUTO DE QUÍMICA DA UNIVERSIDADE DE SÃO PAULO
}

\author{
Carmen Fernandez*, José Otavio Baldinato, Peter W. Tiedemann e Mauro Bertotti \\ Instituto de Química, Universidade de São Paulo, CP 26077, 05513-970 São Paulo - SP, Brasil
}

Recebido em 24/4/07; aceito em 11/1/08; publicado na web em 13/8/08

\begin{abstract}
CHEMISTRY CONCEPTS HELD BY FRESHMEN STUDENTS OF THE INSTITUTE OF CHEMISTRY, UNIVERSITY OF SÃO PAULO. A diagnostic instrument was developed to evaluate the basic chemistry concepts held by freshmen students of the three Chemistry undergraduate courses offered by the University of São Paulo. The instrument minimizes the use of algorithms or memorization by students and values high-order cognitive skills. Analysis of the students' performances reveals systematic use of "displacement reaction" as an algorithm and a mechanical use of Le Chatelier's Principle. Failure in comprehending the chemical equation and chemical language drives students to alternative models for chemical reactions in aqueous solution. For instance, reaction would occur between "ionic pairs" and/or between species situated in separate compartments.
\end{abstract}

Keywords: displacement reaction; chemical language; chemical reaction models.

\section{INTRODUÇÃO}

A formação do químico no Brasil tem sido tema de intensas discussões e análises nos últimos anos, promovidas pela Sociedade Brasileira de Química (SBQ), ${ }_{1}$ o que resultou na consolidação de dois importantes documentos: Eixos Mobilizadores em Química, ${ }^{2}$ de 2003, e A Formação do Químico, ${ }^{3}$ de 2004, como desdobramento do primeiro documento. Dentre os seis Eixos Mobilizadores, quatro têm relação direta com a formação do Químico: a formação de recursos qualificados; o estímulo ao empreendedorismo e à interdisciplinaridade; a desconcentração regional e o combate à endogenia, e a aproximação pró-ativa da academia com a atividade econômica. ${ }^{4}$ A sociedade dos químicos tem assim revelado uma grande preocupação com a formação de pessoal qualificado para sua função.

Por outro lado, os resultados dos nossos estudantes na faixa do Ensino Médio revelam uma situação, no mínimo, preocupante, pois o Brasil figurou em $40^{\circ}$ lugar entre 41 países no teste de Ciências e Matemática do Programa Internacional de Avaliação de Alunos (PISA, 2003). ${ }^{5}$ Esse programa não só avalia os conhecimentos e habilidades dos alunos, mas também seus hábitos de estudo, suas motivações e suas preferências por diferentes tipos de situações de aprendizado. Examina também a capacidade dos estudantes de organizar e gerir seu aprendizado, o que requer consciência da própria capacidade de raciocínio e de estratégias e métodos de aprendizado.

Esse dado resulta, em parte, de uma intensa expansão do Ensino Médio no Brasil nos últimos anos, sem a devida melhoria na qualidade desse nível de ensino. "Em 1991 havia 3,8 milhões de estudantes matriculados no Ensino Médio e, com uma expansão crescente, em 1996 havia 5,7 milhões, em 1999, 7,7 milhões e em 2005 esse número foi de 9 milhões de alunos, segundo os dados do Censo Escolar. ${ }^{6}$ Essa expansão nos números, no entanto, não foi seguida de uma melhoria proporcional na qualidade da educação no mesmo período." Essa expansão foi acompanhada por um crescimento também significativo de cursos de nível superior (entre eles, cursos de formação de professores) para atender a essa demanda de egressos do Ensino Médio. Tais cursos, entretanto, sofrem também com o mesmo problema da falta de qualidade. Portanto, não é necessária uma análise muito profunda

\footnotetext{
*e-mail: carmen@iq.usp.br
}

para concluir que os resultados apresentados pelos nossos estudantes ao final do Ensino Médio têm, entre outras causas, a baixa qualidade da preparação dos professores em Instituições de Ensino Superior e, conseqüentemente, a baixa qualidade do ensino que recebem. Logo, enquanto essa situação persistir, os estudantes egressos do Ensino Médio deverão ter suas dificuldades trabalhadas e solucionadas nos seus futuros cursos de graduação.

Da mesma maneira que outros cursos de nível superior, os cursos de graduação em Química têm, assim, de lidar com essa realidade e tentar contribuir para o rompimento desse ciclo de professores de Ensino Médio com formação deficitária e alunos desestimulados e com uma formação em Química sofrível. Dentro desse contexto, parece natural imaginar que os docentes atuantes nos cursos de Graduação em Química têm tido maiores dificuldades com seus alunos atualmente, e essa situação tem se agravado, especialmente, nas disciplinas iniciais do curso.

Na tentativa de minimizar futuros problemas, uma solução é a tentativa de diagnóstico de problemas com conceitos químicos no início do curso para que os mesmos possam ser trabalhados pelos docentes nas disciplinas iniciais. Essa é uma das soluções descritas na literatura, não apenas em cursos de Química, mas em outros cursos, onde disciplinas como, por exemplo, de Química Geral atendem uma gama diversificada de estudantes com diferentes perfis educacionais e sociais. ${ }^{7}$ Instrumentos têm sido elaborados com esse propósito e, além de diagnosticar, alguns estudos apresentam propostas de cursos de recuperação especialmente desenvolvidos para diminuir a distância entre o desempenho esperado dos alunos e aquele real. Os resultados, entretanto, não são conclusivos. Num desses estudos, por exemplo, conclui-se que um programa de recuperação teve pouco efeito no desempenho dos estudantes num curso de química. ${ }^{8}$ Apesar disso, parece-nos importante realizar um diagnóstico do conhecimento dos estudantes, especialmente no contexto a que se refere este estudo, durante o início da implementação de um curso noturno, que se desenvolve em paralelo ao curso diurno, já tradicional na instituição investigada.

Nesse sentido, o Instituto de Química da Universidade de São Paulo (IQ-USP) tem manifestado preocupação com a formação de seus estudantes, em particular após a ampliação de suas vagas com a criação de dois novos cursos, ambos noturnos: Licenciatura em Química e Bacharelado em Química Ambiental, iniciados em 2003. 
A procura por estes cursos, medida pelo número de candidatos inscritos no primeiro vestibular, em 2003, foi relativamente baixa (aproximadamente 3 candidatos/vaga para Licenciatura e 5,5 para Química Ambiental) em comparação com a relação candidato/vaga do curso do Diurno (estável entre 10 e 11 candidatos/vaga há vários anos). Apesar de esses números terem tido melhoras significativas nos anos posteriores, discutiram-se, na época, propostas para minimizar o impacto da qualificação dos ingressantes no desempenho nos cursos de graduação.

Uma dessas propostas será apresentada neste artigo. Trata-se de uma avaliação que passou a ser realizada com os ingressantes do noturno e, nos anos subseqüentes, também com os alunos do diurno, que passou a ser conhecida como Verificação de Conhecimentos.

O objetivo dessa prova não era simplesmente saber se os alunos eram capazes de resolver problemas tradicionais, que aparecem em livros didáticos do ensino médio de Química, mas sim, avaliar a capacidade de relacionar fatos, manipular dados tabelados, reconhecer a linguagem química e ainda, revelar certas concepções dos estudantes sobre conceitos químicos. Objetivou-se escapar das armadilhas de questões que pudessem permitir que o aluno se valesse apenas de uso de algoritmos, costumeiramente presentes em provas tradicionais de Química. Em tais questões, o estudante mobiliza habilidades cognitivas de baixa ordem e, muitas vezes, só necessita de memorização. É fato recorrente na literatura que diferentes tipos de questões avaliam habilidades distintas. ${ }^{9}$ Assim, são conhecidas questões HOCS (high-order cognitive skills) e LOCS (low-order cognitive skills). ${ }^{10}$ As questões HOCS são problemas não familiares ao estudante, que requerem para a sua solução, além de conhecimento teórico, habilidades de aplicação e análise, capacidade de síntese, assim como o estabelecimento de conexões entre distintos conteúdos. Questões LOCS requerem apenas uma retomada de informação ou uma simples aplicação da teoria ou conhecimento a situações e contextos familiares, podendo ser resolvidas por meio de algoritmos.

Buscou-se assim elaborar questões que pudessem diagnosticar problemas conceituais dos estudantes. A literatura em Ensino de Química tem relatado uma vasta quantidade de concepções dos estudantes, ou, como ficaram mais conhecidas, concepções alternativas, que são explicações que os estudantes elaboram e utilizam e que são diferentes daquelas aceitas pela comunidade científica. ${ }^{11}$ Muitas dessas concepções passam despercebidas durante os anos de formação dos estudantes e vão se acumulando com o passar dos anos de sua vida educativa.

Seria importante que os professores universitários tivessem ciência dessas concepções nos seus alunos quando ministram uma determinada disciplina e das barreiras que elas criam para uma aprendizagem significativa. Esse conhecimento faria com que eles pudessem ajudar seus alunos num aprendizado mais efetivo. Essas concepções estão disseminadas e, diferente do que se poderia supor, não ocorrem apenas entre os estudantes mais fracos.

Dentro de uma abordagem construtivista, o conhecimento é construído na mente do aprendiz, e, portanto, a aprendizagem é construída baseada nas idéias pré-existentes na estrutura cognitiva dos alunos, mesmo que essas idéias sejam muito distintas das idéias que o professor tenha em mente (as quais são, presumivelmente, "mais científicas"). ${ }^{11}$ De uma forma bastante geral, a aprendizagem pode ser vista como dois processos separados: a adição de novos conhecimentos a uma estrutura pré-existente de idéias e a reestruturação dessa estrutura conceitual. Sendo assim, para melhor auxiliar a aprendizagem de um aluno, é importante considerar o que esse aluno já sabe sobre aquele assunto, ou seja, o seu conhecimento prévio. A aprendizagem se dá quando o estudante consegue realizar conexões entre o conteúdo do currículo que está sendo introduzido pelo professor e sua estrutura cognitiva prévia. Sendo assim, uma aprendizagem efetiva irá depender tanto das idéias prévias dos estudantes quanto da qualidade das atividades desenvolvidas na aula.

Dentro desse contexto, saber quais as idéias prévias dos ingressantes nos cursos de Química tem como objetivo realizar um diagnóstico e reportar aos professores das disciplinas iniciais as principais concepções desses estudantes, com o intuito de propiciar uma aprendizagem mais efetiva e conseqüentemente uma melhoria na sua formação.

Além disso, numa primeira etapa da Verificação de Conhecimentos, os resultados gerais obtidos foram encaminhados a cada um dos ingressantes, anexando-se também o conteúdo de Química avaliado em cada questão e a nota atribuída ao aluno. Desta forma, os alunos puderam comparar o desempenho individual com o desempenho coletivo e avaliar as deficiências diagnosticadas pela Verificação de Conhecimentos. Numa etapa posterior, instituiu-se um programa de estudos dirigidos, denominado "Conceitos Básicos de Química Estudo Dirigido - 2003”. Durante 6 sábados, num período de 3 h, monitores e docentes revezaram-se com o intuito de discutir aspectos considerados essenciais para o bom acompanhamento das disciplinas de Química do primeiro semestre letivo. Nessa atividade, problemas sobre tópicos básicos envolvendo compostos, moléculas, átomos e íons, misturas e soluções, soluções aquosas e precipitação, estequiometria de reações químicas, entre outros, foram abordados e discutidos em sala de aula. Nesses encontros, privilegiou-se a resolução de problemas em grupos pequenos, com posterior discussão no grupo maior. Professores e monitores se revezavam no direcionamento das dúvidas. A participação foi voluntária, contou com alunos de ambos os períodos (maioria do Noturno), teve freqüência variada e saldo positivo, conforme relatos individuais.

Neste trabalho, apresentamos uma análise realizada com as respostas às questões da Verificação de Conhecimentos com os ingressantes aos cursos de Bacharelado e Licenciatura em Química (diurnos), Bacharelado em Química Ambiental e Licenciatura em Química (noturnos) no IQ-USP e as principais dificuldades encontradas em conceitos de química com esses estudantes.

\section{METODOLOGIA}

A avaliação denominada Verificação de Conhecimentos foi realizada pela primeira vez em 2003, tendo sido composta de 16 questões conceituais abrangendo diferentes tópicos de Química normalmente ministrados no Ensino Médio. Cada questão deveria ter sua resposta justificada. A avaliação foi estendida também aos alunos ingressantes do diurno e, dessa forma, foi possível obter dados comparativos dos diferentes cursos. A partir de 2004 o instrumento de avaliação foi modificado e passou a consistir em 25 questões de múltipla escolha, respondidas em folhas de leitura óptica fornecidas pela Fuvest e, desde então, tem sido consistentemente aplicado aos ingressantes dos cursos noturno e diurno. O processamento desse material permite a obtenção de informações bastante detalhadas sobre o índice de respostas por questão. A Verificação de Conhecimentos tem sido amplamente discutida com os ingressantes, aos quais se destacou a necessidade de enfoque responsável da proposta para fins de obtenção de resultados fidedignos. A avaliação é costumeiramente realizada na semana seguinte à semana de recepção aos calouros. Fração expressiva dos ingressantes tem participado da avaliação, de forma que os resultados são altamente representativos.

As questões dessa prova foram elaboradas levando-se em consideração dados da literatura sobre concepções dos estudantes em diferentes temas da química. ${ }^{12}$ Alguns temas reconhecidamente problemáticos foram abordados nessas questões, com intuito de diagnosticar as concepções dos ingressantes nos cursos. Dentre essas dificuldades, foram abordadas nas questões: a extrapolação de 
propriedades macroscópicas para átomos isolados, ${ }^{13}$ modelos sobre mudanças de estado, ${ }^{14}$ dificuldades em aceitar que o espaço entre as partículas é vazio; problemas com o entendimento de substâncias e suas representações; equilíbrio químico, ${ }^{15}$ problemas com a compreensão da dissociação iônica, ${ }^{13,16}$ justificativas para a diferença na força de ácidos; resolução de problemas, etc.

As respostas às questões dadas à prova aberta de 2003 foram todas analisadas e categorizadas. As respostas aos testes de múltipla escolha nos anos seguintes também foram analisadas.

Para este estudo, foram selecionadas algumas das questões que apresentaram maiores índices de erro, ou cuja correção permitiu a detecção de falhas sistemáticas nas respostas de número considerável de alunos. Cada questão da prova de 2003 tinha valor de 2 pontos, enquanto que na prova dos outros anos, as respostas eram divididas apenas entre certas e erradas. Assim, os primeiros critérios utilizados para seleção das perguntas que seriam analisadas foram o de média para a questão abaixo de 1,0 em 2003 e de índice de acerto inferior a $50 \%$ nos anos subseqüentes. Na seqüência foram escolhidas, entre estas questões, aquelas cuja leitura das respostas permitia a percepção de falhas sistemáticas, com erros que se repetiam nas provas de pelo menos $20 \%$ dos alunos de uma turma. Estes erros comuns foram considerados concepções alternativas que os alunos apresentavam.

Os resultados obtidos na Verificação de Conhecimentos foram também comparados, para cada estudante, em relação ao seu desempenho no Vestibular.

\section{RESULTADOS E DISCUSSÃO}

\section{Análise geral do desempenho na prova de verificação de conhecimentos e no exame vestibular}

O gráfico apresentado na Figura 1 corresponde ao desempenho médio dos ingressantes nas três diferentes carreiras (Bacharelado e Licenciatura-Diurno, Bacharelado em Química Ambiental-Noturno e Licenciatura-Noturno) de 2003 a 2006. Um primeiro aspecto a ser destacado relaciona-se à menor média na Verificação de Conhecimentos observada em 2003 para todas as carreiras. Tal fato pode ser justificado considerando-se a natureza da avaliação neste ano e nos que se seguem. Apesar de o nível de dificuldade ser praticamente o mesmo, em provas objetivas deve-se levar em conta o acerto ocasional, fator inexistente na avaliação aplicada em 2003, onde os estudantes tinham de justificar suas respostas.

Embora haja questionamentos sobre o efeito preditivo do vestibular, investigou-se a possibilidade de haver alguma correlação entre o desempenho dos alunos na Verificação de Conhecimentos e dados relacionados ao vestibular. As Figuras 2 e 3 apresentam informações sobre a procura no vestibular (relação candidato/vaga) e a nota de corte (número mínimo de pontos para a classificação para a $2^{\mathrm{a}}$ fase do vestibular) para os três diferentes cursos no período considerado. A

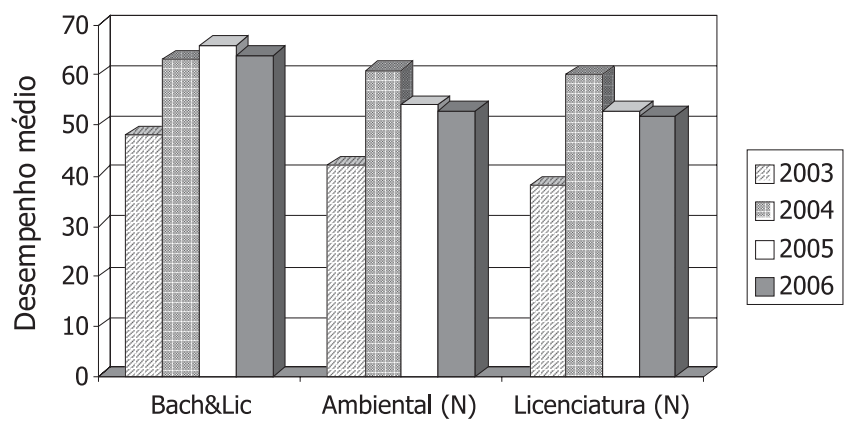

Figura 1. Desempenho médio dos estudantes na Verificação de Conhecimentos para os três cursos de graduação do IQ-USP entre os anos 2003 e 2006 análise destes dados mostra que, tanto a procura quanto a nota de corte, são relativamente maiores no curso Diurno em comparação com os cursos do Noturno, com exceção em 2004, quando houve uma demanda excepcional pelo curso de Licenciatura-Noturno. Apesar dessa maior procura pela Licenciatura-Noturno em 2004, ainda assim a nota de corte nesse ano foi maior para o diurno. Há, portanto, certa correlação entre o melhor desempenho dos alunos do Diurno na Verificação de Conhecimentos nestes 4 anos e os índices associados à procura pelos cursos e as notas obtidas na primeira fase do vestibular.

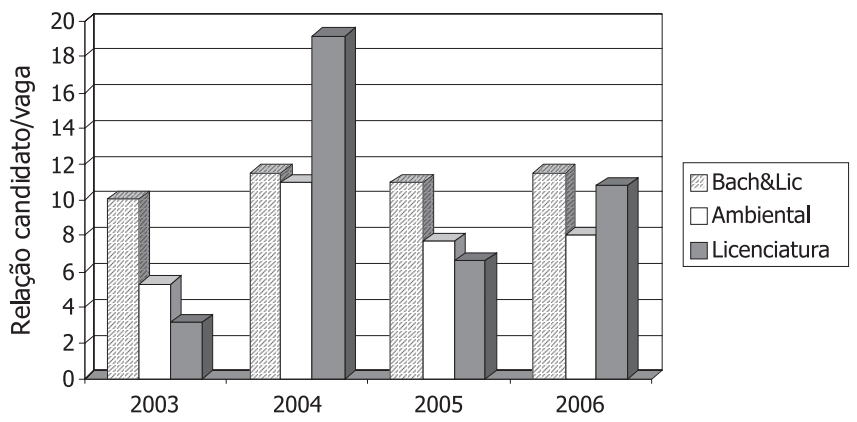

Figura 2. Relação candidato/vaga para os três cursos de graduação do IQUSP entre os anos 2003 e 2006

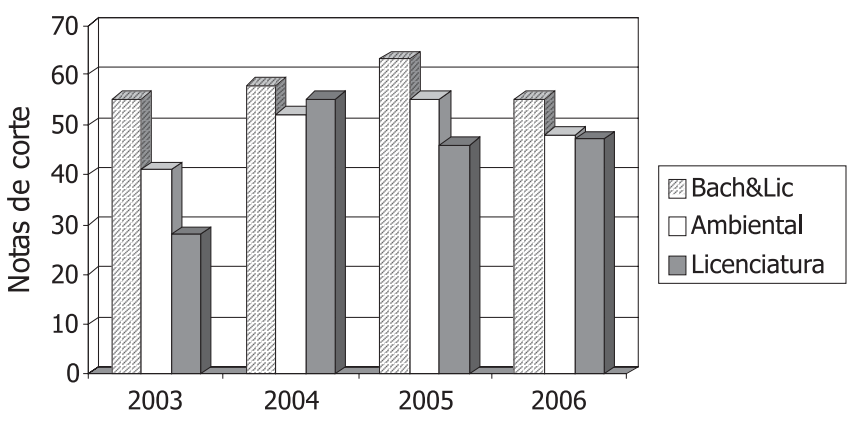

Figura 3. Notas de corte da primeira fase do vestibular FUVEST para os três cursos de graduação do IQ-USP entre os anos 2003 e 2006

A Figura 4 apresenta um gráfico que relaciona os resultados das notas dos estudantes na Verificação de Conhecimentos e na prova de Química da $2^{2}$ fase do vestibular em 2005. O ajuste linear entre as notas das duas avaliações resulta no coeficiente de correlação 0,65 . Algumas hipóteses podem ser consideradas para justificar por que essa correlação não foi mais elevada. As duas provas apresentam objetivos distintos. O vestibular é uma prova eliminatória, na qual é necessário selecionar estudantes para o ingresso na Universidade. Para isso, a banca examinadora da Fuvest elabora 10 questões dissertativas abrangendo alguns conceitos químicos considerados mais importantes para a formação geral do cidadão; afinal, o vestibular se destina a selecionar candidatos para várias carreiras e não apenas para futuros profissionais de química. Isso influencia também os critérios adotados para a correção e a atribuição de pontos pela banca examinadora. A Verificação de Conhecimentos, por sua vez, tem objetivos bem distintos: diagnosticar problemas relacionados à compreensão de conceitos químicos considerados fundamentais para o futuro químico. O maior número de questões (25 versus 10) permite a avaliação de uma gama mais ampla de conceitos, em uma profundidade maior que aquela do vestibular.

As questões da Verificação de Conhecimentos foram elaboradas de modo a minimizar a possibilidade de serem resolvidas mecanicamente, apenas pela aplicação de algoritmos, por exemplo. Também foram evitadas questões que envolvessem apenas memorização - sendo que na segunda fase do vestibular às vezes são atribuídos pontos aos candidatos como resultado mais da memorização do que 


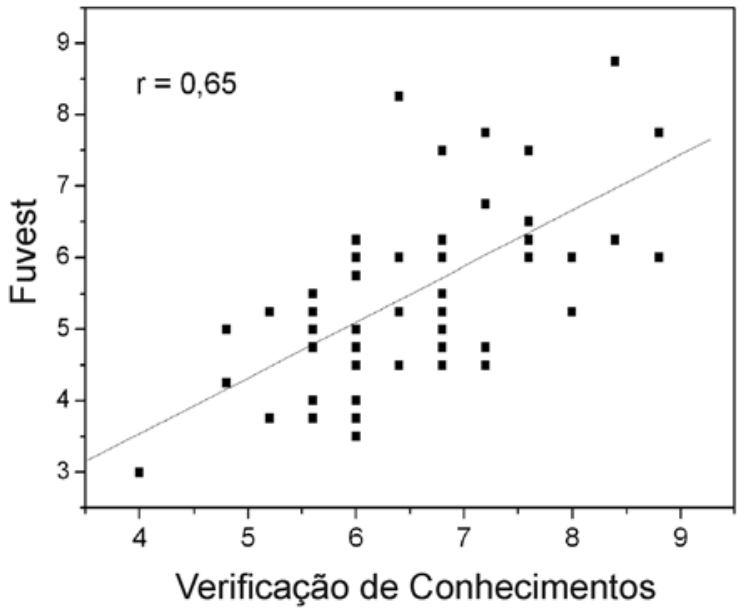

Figura 4. Relação entre os desempenhos na Verificação de Conhecimentos e a prova de Química da 2 a fase do vestibular, para os ingressantes no ano de 2005

do uso de habilidades cognitivas mais complexas. Finalmente, o fato de a prova da segunda fase da Fuvest ser dissertativa e a Verificação de Conhecimentos consistir em testes de múltipla escolha também contribui para que a correlação entre as notas de uma e de outra se afaste de 1 . A partir do valor do coeficiente de correlação, conclui-se, portanto, que os dados não se relacionam suficientemente de modo a se poder dispensar a Verificação de Conhecimentos e basear-se exclusivamente na avaliação da Fuvest como diagnóstico. A Verificação de Conhecimentos traz, assim, uma informação diferenciada, que serve aos nossos propósitos com esses alunos.

Investigações sobre as concepções de alguns conceitos de química dos ingressantes nos cursos de graduação do IQ-USP

Na Tabela 1 compilamos os dados de todas as turmas nos principais problemas apresentados por elas. Essa tabela mostra as por- centagens de respostas dos alunos dos diferentes cursos nos anos de 2003 a 2006, que apresentaram algum tipo de concepção alternativa discriminada na primeira coluna da tabela.

Os resultados com a prova de Verificação de Conhecimentos mostram que, apesar de as médias gerais dos alunos do Bacharelado, Química Ambiental e Licenciatura estarem numa ordem decrescente, ao se analisar os tipos de erros cometidos em cada questão, percebe-se uma maior homogeneidade entre os estudantes. Das respostas dissertativas às questões analisadas na prova de Verificação de Conhecimentos de 2003 podemos afirmar que não houve uma diferenciação significativa entre os alunos dos três cursos quanto aos erros apresentados. As maiores dificuldades dos alunos apareceram nas mesmas questões e as concepções alternativas são semelhantes nesses estudantes, o que, aliás, corrobora outros dados da literatura os quais sugerem que essas concepções têm a característica de serem estáveis, difíceis de serem mudadas e apresentarem um caráter generalizado entre os estudantes. ${ }^{12}$

Como somente a prova de 2003 trazia questões abertas, iremos nos reportar a algumas respostas dessa turma para exemplificar os erros cometidos pelos estudantes. Para as demais turmas, mostramos somente as porcentagens dos erros. Entretanto, acreditamos que, se tivéssemos as respostas justificadas dos alunos dos demais anos, teríamos erros semelhantes em todas as turmas analisadas, a julgar pelas porcentagens dos erros encontradas. A seguir apresentamos uma análise dessas respostas.

O exame de 2003 foi feito por 109 alunos, o que representa $91 \%$ dos ingressantes naquele ano. Desses, 57 estavam matriculados no curso diurno de Licenciatura e Bacharelado em Química, 28 no curso noturno de Bacharelado em Química Ambiental e 24 no curso noturno de Licenciatura em Química.

\section{Macro vs micro}

Falhas na distinção entre propriedades macro e microscópicas dos materiais podem ser analisadas pelas respostas dadas à questão a seguir:

Tabela 1. Concepções dos estudantes ingressantes de Química no IQ-USP em 2003 a 2006: Bacharelado diurno (B); Química Ambiental noturno (QA); Licenciatura noturno (L)

\begin{tabular}{|c|c|c|c|c|c|c|}
\hline Itens analisados & Problemas encontrados nas respostas às questões & & $\begin{array}{c}2003 \\
\mathrm{~N}=109 \%\end{array}$ & $\begin{array}{c}2004 \\
\mathrm{~N}=93 \%\end{array}$ & $\begin{array}{c}2005 \\
\mathrm{~N}=109 \%\end{array}$ & $\begin{array}{c}2006 \\
\mathrm{~N}=99 \%\end{array}$ \\
\hline \multirow{2}{*}{ Macro vs micro } & \multirow{2}{*}{$\begin{array}{l}\text { Um átomo de um fio metálico conduz eletricidade - tem } \\
\text { alta densidade - apresenta alto PF }\end{array}$} & $\mathrm{B}$ & 90 & 35 & 26 & 27 \\
\hline & & $\mathrm{L}$ & 92 & 43 & 42 & 56 \\
\hline \multirow{3}{*}{ Mudança de estado } & As bolhas da água fervente são constituídas de $\mathrm{O}_{2}, \mathrm{CO}_{2}$, & $\mathrm{B}$ & 32 & 11 & 28 & 22 \\
\hline & \multirow{2}{*}{$\begin{array}{l}\mathrm{N}_{2} \text { ou } \mathrm{H}_{2} \text { - de } \mathrm{H}_{2} \text { ou } \mathrm{O}_{2} \text { - gases dissolvidos - ar atmos- } \\
\text { férico }\end{array}$} & QA & 29 & 8 & 28 & 26 \\
\hline & & $\mathrm{L}$ & 33 & 10 & 19 & 35 \\
\hline \multirow{3}{*}{$\begin{array}{l}\text { Reconhecimento de íons e formação } \\
\text { de sais pouco solúveis }\end{array}$} & \multirow{3}{*}{$\begin{array}{l}\text { Não conseguiram predizer a ocorrência de uma reação a } \\
\text { partir de dados de solubilidade }\end{array}$} & $\mathrm{B}$ & 30 & 26 & 46 & 56 \\
\hline & & QA & 39 & 46 & 48 & 37 \\
\hline & & $\mathrm{L}$ & 38 & 43 & 42 & 56 \\
\hline \multirow{3}{*}{$\begin{array}{l}\text { Variação de energia e algoritmo da } \\
\text { reação de "dupla troca" }\end{array}$} & \multirow{3}{*}{ Mecanização do algoritmo da reação de "dupla troca" } & $\mathrm{B}$ & 37 & 65 & 43 & 76 \\
\hline & & QA & 43 & 69 & 79 & 59 \\
\hline & & $\mathrm{L}$ & 42 & 57 & 77 & 74 \\
\hline \multirow[t]{2}{*}{ Determinação de pH } & \multirow{2}{*}{$\begin{array}{l}\text { Acidez é determinada exclusivamente pelo número de } \\
\text { hidrogênios ionizáveis }\end{array}$} & QA & 18 & 23 & 55 & 41 \\
\hline & & $\mathrm{L}$ & 17 & 43 & 50 & 48 \\
\hline \multirow{3}{*}{ Equilíbrio químico } & \multirow{3}{*}{ Princípio de Le Chatelier como algoritmo } & B & 70 & 67 & 87 & 88 \\
\hline & & QA & 79 & 100 & 93 & 63 \\
\hline & & $\mathrm{L}$ & 88 & 91 & 100 & 83 \\
\hline
\end{tabular}


Um fio metálico tem as seguintes características:
a) conduz eletricidade
b) tem cor marrom
c) é maleável
d) apresenta alto ponto de fusão
e) apresenta alta densidade

Suponha que você pudesse isolar um átomo do fio metálico.

Qual(is) das cinco propriedades este átomo teria?

Pelos dados apresentados na Tabela 1, observamos o pior desempenho da turma de 2003. O fato de um único átomo não poder apresentar propriedades como condutividade elétrica, cor, maleabilidade ou ainda mudança de estado físico foi compreendido por apenas $c a .10 \%$ da turma. Nessa turma, 54\% das respostas atribuíam "alta densidade" a um átomo de um elemento metálico isolado. Esta propriedade não constava nas alternativas da questão nos demais anos, quando o índice de erro foi consideravelmente menor. A segunda propriedade mencionada como sendo característica de um átomo isolado foi "alto ponto de fusão". Essa é uma concepção descrita na literatura para estudantes de outros países e em diferentes níveis de ensino. ${ }^{13}$

Algumas respostas representativas dos estudantes podem ser observadas a seguir:

"Ele teria a propriedade b (tem cor marrom), pois reflete esta faixa de luz." (prova 11)

"Esse átomo conduziria eletricidade e apresentaria alto ponto de fusão. Propriedades ligadas ao elemento e não à matéria em si." (prova 13)

"Conduziria eletricidade, já que poderia ganhar ou perder elétrons." (prova 26)

"Apenas os itens $(a)$ e $(d)$, pois eles não dependem da quantidade, da forma ou da disposição dos átomos no recipiente, ou seja, são propriedades microscópicas." (prova 52)

Na prova de múltipla escolha existia a alternativa que indicava a possibilidade de que nenhuma das propriedades macroscópicas apresentadas fosse encontrada no átomo isolado; acredita-se que esta opção direta tenha facilitado a questão, induzindo os alunos a um raciocínio mais crítico. Apesar disso, temos índices de erro significativos nos demais anos nessa questão, variando de 26 a $56 \%$. Comparando os três diferentes cursos, as maiores porcentagens de erros são encontradas nos alunos da Química Ambiental e Licenciatura noturnos.

\section{Mudança de estado}

Ao serem questionados sobre a composição das bolhas na água fervente, na questão apresentada abaixo, vários problemas foram encontrados.

Considere a seguinte situação: Um recipiente com água é levado à chama de um bico de gás e a partir de certo momento a água entra em ebulição. Qual é a composição das bolhas na água fervente?

As respostas dadas a essa questão incluíam vários gases entre eles, $\mathrm{H}_{2} \mathrm{~N}_{2} \mathrm{O}_{2} \mathrm{CO}_{2}$, etc. Algumas respostas também mencionavam $\mathrm{o}$ ar. Outros alunos diziam que as bolhas apresentam, além de algum desses gases, também a resposta esperada, vapor de água.

A concepção alternativa de que ligações covalentes podem ser rompidas em mudanças de estado físico já foi reportada nos trabalhos de Treagust ${ }^{17}$ e Osborne e Cosgrove. ${ }^{14}$
"A composição das bolhas é de hidrogênio e oxigênio, na proporção de 2 hidrogênios para 1 oxigênio.” (prova 10)

"É composta principalmente pelos gases antes dissolvidos na água $\left(\mathrm{CO}_{2}, \mathrm{~N}_{2}, \mathrm{O}_{2}\right.$, etc $)$, cuja solubilidade é inversamente proporcional à temperatura. Deve haver ainda certa quantidade de água no estado gasoso." (prova 94)

"As bolhas na água fervente são compostas por água no estado gasoso e líquido, além de também haverem nelas gases presentes no ar como $\mathrm{O}_{2}$ e o $\mathrm{N}_{2}$ ", (prova 43)

"Gradualmente, conforme a temperatura, o "aglomerado" de moléculas de água interligadas comporta certa quantidade de gás dissolvido. Este gás pode ser gases atmosféricos, tais como oxigênio ou gás carbônico. Com o aumento da temperatura, a solubilidade desses gases cai bruscamente e então eles são liberados num processo Fisico-Químico de ascenção das bolhas." (prova 58)

Na Tabela 1 observamos que os erros para essa questão também foram maiores na turma de 2003. Na provas de múltipla escolha esses erros estiveram entre 8 e $35 \%$ e não há um perfil diferenciado entre os diferentes cursos, exceto o melhor desempenho apresentado pela turma de 2004 .

\section{Reconhecimento de íons e formação de sais pouco solúveis}

Outra questão analisada apresentava uma tabela com dados sobre a solubilidade de sais em água. Era necessário o conhecimento de quais elementos compõem algumas das famílias da tabela periódica e a montagem de equações iônicas que descrevessem as reações citadas, o que exigia a interpretação da tabela de íons que se combinariam na formação de sais insolúveis.

Esperávamos que os alunos reconhecessem a formação de precipitados nas alternativas al $\left(\mathrm{Ag}_{2} \mathrm{CO}_{3}\right), a 2\left(\mathrm{BaCrO}_{4}\right)$ e $a 3\left(\mathrm{Ca}_{3}\left(\mathrm{PO}_{4}\right)_{2}\right)$; bem como identificassem a possibilidade de formação de $\mathrm{Ag}_{2} \mathrm{CrO}_{4}$ a

A tabela apresenta informações sobre solubilidade em água de alguns compostos.

\begin{tabular}{|c|c|}
\hline Compostos solúveis & Compostos insolúveis \\
\hline $\begin{array}{l}\text { Compostos dos elementos } \\
\text { do grupo } 1 \text { (metais alcalinos) }\end{array}$ & $\begin{array}{l}\text { - Carbonatos }\left(\mathrm{CO}_{3}^{2-}\right) \text {, cromatos } \\
\left(\mathrm{CrO}_{4}^{2-}\right) \text { e fosfatos }\left(\mathrm{PO}_{4}^{3-}\right) \text {, exceto os } \\
\text { do grupo } 1 \text { e } \mathrm{NH}_{4}^{+}\end{array}$ \\
\hline $\begin{array}{l}\text { - Compostos de amônio } \\
\left(\mathrm{NH}_{4}^{+}\right) \\
\text {- Cloretos }\left(\mathrm{Cl}^{-}\right) \text {, brometos }\end{array}$ & $\begin{array}{l}\text {-Hidróxidos e óxidos, exceto os dos } \\
\text { elementos do grupo } 1 \text { e } 2 \text { (metais } \\
\text { alcalinos e alcalino-terrosos) }\end{array}$ \\
\hline
\end{tabular}

$(\mathrm{Br})$, iodetos $(\mathrm{I})$, exceto os

de $\mathrm{Ag}^{+}$e $\mathrm{Pb}^{2+}$

- Nitratos $\left(\mathrm{NO}_{3}^{-}\right)$

- Sulfatos $\left(\mathrm{SO}_{4}^{2-}\right)$ exceto os de

cálcio, estrôncio, bário,

chumbo e prata

(adaptado de Atkins e Jones)

a) Para os procedimentos relacionados a seguir, indique se ocorre reação, identificando, quando for o caso, o produto formado; escreva, na forma iônica, a equação química que representa a transformação. a1) Uma solução aquosa de $\mathrm{AgNO}_{3}$ é misturada com outra de $\mathrm{Na}_{2} \mathrm{CO}_{3}$.

a2) Uma solução aquosa de $\left(\mathrm{NH}_{4}\right)_{2} \mathrm{CrO}_{4}$ é misturada com outra de $\mathrm{BaCl}_{2}$.

a3) Uma solução aquosa de fosfato de sódio é misturada com outra de cloreto de cálcio.

b) Sugira 2 compostos solúveis que, quando misturados em água, levem à formação de cromato de prata. 
partir de soluções de $\mathrm{AgNO}_{3}$ e $\mathrm{Na}_{2} \mathrm{CrO}_{4}$.

Na turma de 2003, os índices de respostas que indicavam que algumas das reações não ocorreriam foram de $21 \%$ para a reação do item "a1", $14 \%$ para "a2" e $8 \%$ para a reação expressa no item "a3". Apesar de vários alunos apresentarem algum tipo de equação iônica, foi muito freqüente a montagem de equações de "dupla troca" completas. A dificuldade na compreensão da equação iônica já foi reportada anteriormente. ${ }^{18}$

Nos demais anos, os erros se apresentam uniformemente distribuídos nos diferentes anos e nos diferentes cursos, ficando em torno de $45 \%$.

\section{Variações de energia e algoritmo da reação de "dupla troca"}

Uma das questões que tratavam de variações de energia também testava a compreensão de reações químicas em fase aquosa. Da mesma forma que se verificou nas questões que tratavam de previsão de reações em solução aquosa, os resultados aqui obtidos reforçam a idéia de que a descrição de reações químicas por meio de equações iônicas não é hábito dos alunos.

Reações de neutralização são representadas abaixo com os respectivos valores de variação de entalpia:

$$
\begin{aligned}
& \mathrm{HCl}(a q)+\mathrm{KOH}(a q) \rightarrow \mathrm{KCl}(a q)+\mathrm{H}_{2} \mathrm{O} \\
& \mathrm{HNO}_{3}(a q)+\mathrm{NaOH}(a q) \rightarrow \mathrm{NaNO}_{3}(a q)+\mathrm{H}_{2} \mathrm{O}
\end{aligned}
$$

Foi verificado experimentalmente que $\Delta H_{1}=\Delta H_{2}$

a) Justifique a igualdade acima.

b) Para a reação representada por

$\mathrm{HNO}_{3}(a q)+\mathrm{KOH}(a q) \rightarrow \mathrm{KNO}_{3}(a q)+\mathrm{H}_{2} \mathrm{O}$

diga se $\Delta H_{3}$ é igual, menor ou maior que $\Delta H_{1}$. Justifique.

c) $O$ que se pode aprender a partir dessas informações?

$\Delta H_{2}$

Na análise das respostas a essa questão em 2003, não foi possível dividir as concepções alternativas observadas em categorias com fração significativa das respostas. Nesse ano, ca. $38 \%$ dos alunos acertaram a questão. As respostas erradas atribuíam várias explicações para a igualdade entre as variações de energias apresentadas nas reações. Entre os argumentos utilizados, constam que $\Delta H$ é igual porque as energias de ligação dos reagentes das duas reações são iguais, porque as soluções têm mesma concentração, ou ainda porque as espécies são "de mesma valência". Vale lembrar que a questão, em 2003, foi deixada em branco por $36 \%$ dos alunos e que apenas 27 dos 70 alunos com respostas não nulas acertaram a questão. Exemplos de respostas podem ser vistos abaixo.

"A diferença de entalpia das ligações $(\mathrm{K}-\mathrm{Cl}+2 \mathrm{O}-\mathrm{H})-(\mathrm{H}-\mathrm{Cl}$ $+\mathrm{K}-\mathrm{OH}$ ) é igual a diferença das entalpias das ligações ( $\mathrm{Na}$ $\left.\mathrm{NO}_{3}+2 \mathrm{O}-\mathrm{H}\right)-\left(\mathrm{H}-\mathrm{NO}_{3}+\mathrm{Na}-\mathrm{OH}\right)$.” (prova 8$)$

"Ambas acontecem em meio aquoso e tem como produto a água.” (prova 84)

Em 2004, foram simplesmente trocados os íons dos reagentes das reações e foi mantida a pergunta sobre o porquê da igualdade de calor desprendido. As alternativas dadas são as que seguem as reações.

$$
\mathrm{HCl}(a q)+\mathrm{NaOH}(a q) \rightarrow \mathrm{NaCl}(a q)+\mathrm{H}_{2} \mathrm{O}
$$$$
\mathrm{HNO}_{3}(a q)+\mathrm{KOH}(a q) \rightarrow \mathrm{KNO}_{3}(a q)+\mathrm{H}_{2} \mathrm{O}
$$

a) a reação envolvida é sempre de íons $\mathrm{H}^{+}$com ions $\mathrm{OH}$, sem a participação de outros íons. b) a energia de solvatação dos íons $\mathrm{Cl}^{-}$é igual à dos íons $\mathrm{NO}_{3}^{-}$e a dos íons $\mathrm{Na}^{+}$é igual à dos íons $\mathrm{K}^{+}$.

c) as energias de ligação $\mathrm{H}-\mathrm{Cl}$ e $\mathrm{H}-\mathrm{NO}_{3}$ são iguais, bem como as de $\mathrm{Na}-\mathrm{OH}$ e $\mathrm{K}-\mathrm{OH}$.

d) as entalpias de formação de $\mathrm{NaCl}$ e $\mathrm{KNO}_{3}$ são iguais e $\mathrm{H}_{2} \mathrm{O}$ é comum nas duas reações.

e) nos dois casos, trata-se de reações de dupla troca, envolvendo ions de mesma carga.

No gráfico da Figura 5 apresenta-se a distribuição das respostas a essa questão. Observa-se que $26 \%$ dos estudantes assinalaram a alternativa correta. Por comparação com os resultados da turma de 2003, acredita-se que a distribuição quase que igualitária das respostas atribuídas à questão não é aleatória, mas resulta da presença de concepções alternativas trazidas pelos alunos. Uma grande parcela dos alunos atribui variação de entalpia unicamente à diferença de energia entre as ligações dos produtos e reagentes e, para isso, sempre efetuam reações de "dupla troca" completas, desprezando a possibilidade de que algumas das ligações esperadas entre os produtos não se formem, ou mesmo que em meio aquoso, já não existam mais algumas das ligações esperadas entre os reagentes, cujos íons constituintes se encontram separados por solvatação. Não é hábito dos alunos pensar nas reações sob a forma iônica, considerando apenas os componentes que realmente participam das reações formando produtos e ligações. ${ }^{18}$

Turmas de 2004

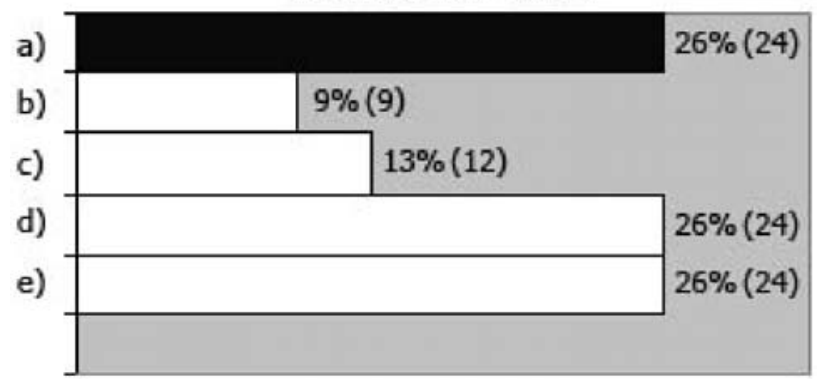

Figura 5. Distribuição das respostas à questão sobre igualdade de calor desprendido numa reação de neutralização; alunos de 2004

Observando-se o desempenho de todas as turmas, é nítido que existem problemas com os conceitos tratados nessa questão. A porcentagem dos erros varia de 40 a $80 \%$ e é igualmente alta para todas as turmas nos diferentes anos.

\section{Determinações de pH}

Foram encontradas diversas falhas conceituais entre as respostas. A Tabela 2 apresenta as principais categorias nas quais as respostas puderam ser divididas.

Apenas 8\% dos alunos da turma de 2003 citaram o termo "grau de ionização" como fator importante na determinação da acidez de uma solução. A questão cuja correção aponta a impopularidade deste conceito é a que segue.

Três estudantes têm opiniões diferentes quanto ao valor de $\mathrm{pH}$ de soluções aquosas de concentração $0,1 \mathrm{~mol} \mathrm{~L}^{-1}$ de $\mathrm{HCl}, \mathrm{H}_{3} \mathrm{PO}_{4}$ e $\mathrm{H}_{3} \mathrm{C}$-COOH. O primeiro estudante afirma que as soluções têm o mesmo $\mathrm{pH}$. O segundo acredita que os valores de $\mathrm{pH}$ das três soluções sejam diferentes. O terceiro opina que apenas duas soluções tenham o mesmo $\mathrm{pH}$. Que argumentos você usaria para defender a opinião correta?

Cerca de $21 \%$ das respostas insinuavam que a acidez é determinada exclusivamente pelo número de hidrogênios ionizáveis na 
Tabela 2. Respostas da questão de pH de soluções aquosas (turma de 2003) divididas em categorias e índices de recorrência

\begin{tabular}{|c|c|c|c|c|}
\hline & $\begin{array}{l}\text { Bacharelado e } \\
\text { Licenciatura \% }\end{array}$ & $\begin{array}{c}\text { Ambiental } \\
\%\end{array}$ & $\begin{array}{c}\text { Licenciatura } \\
\%\end{array}$ & $\begin{array}{c}\text { Todos } \\
\%\end{array}$ \\
\hline $\begin{array}{l}\text { Acidez determinada exclu- } \\
\text { sivamente pelo número de } \\
\text { hidrogênios ionizáveis. }\end{array}$ & 28 & 11 & 17 & 21 \\
\hline $\begin{array}{l}\mathrm{H}_{3} \mathrm{C}-\mathrm{COOH} \text { tem } 3 \\
\text { hidrogênios ionizáveis. }\end{array}$ & 9 & 7 & 0 & 6 \\
\hline $\begin{array}{l}\text { Acidez do } \mathrm{HCl} \text { é igual à } \\
\text { do } \mathrm{H}_{3} \mathrm{C}-\mathrm{COOH} \text {. }\end{array}$ & 21 & 7 & 13 & 16 \\
\hline $\begin{array}{l}\text { Mencionaram } \alpha \text { ou "grau } \\
\text { de ionização" e acertaram } \\
\text { a questão. }\end{array}$ & 7 & 7 & 4 & 6 \\
\hline $\begin{array}{l}\text { Mencionaram } \alpha \text { ou "grau } \\
\text { de ionização" e erraram a } \\
\text { questão. }\end{array}$ & 4 & 0 & 0 & 2 \\
\hline $\begin{array}{l}\mathrm{H}_{3} \mathrm{C}-\mathrm{COOH} \text { é orgânico, } \\
\text { logo, é fraco. }\end{array}$ & 12 & 7 & 0 & 8 \\
\hline
\end{tabular}

molécula. Outros $16 \%$ dos alunos responderam que o $\mathrm{pH}$ medido para a solução de $\mathrm{HCl}$ seria igual ao da solução contendo $\mathrm{H}_{3} \mathrm{CCOOH}$ em mesma concentração.

"Para defender a opinião de que apenas duas soluções têm o mesmo $\mathrm{pH}$, diria que o número de íons $\mathrm{H}^{+}$dissociados nas soluções de ácido fosfórico e ácido acético são iguais e três vezes maiores do que o número de íons $H^{+}$na solução de HCl." (prova 20)

"A opinião correta é a do terceiro estudante pois o $\mathrm{HCl}$ e o $\mathrm{CH}_{3} \mathrm{COOH}$ possui cada um hidrogênio ionizável, mas o $\mathrm{H}_{3} \mathrm{PO}_{4}$ possui dois hidrogênios ionizáveis, logo o seu pH será diferente das demais soluções." (prova 92)

" $\mathrm{O}$ pH das três soluções serão de mesmo valor pois $\mathrm{pH}$ $=-\log \left[\mathrm{H}^{+}\right]$, e a concentração das 3 soluções são iguais." (prova 98)

Essa questão também teve um índice de erro alto, independentemente de curso e/ou ano. As porcentagens de erro estão na faixa de $45 \%$. Interessante observar que nessa questão em particular, os alunos que responderam à questão aberta (turma de 2003) tiveram um desempenho melhor que os demais.

\section{Equilíbrios químicos}

A questão a seguir buscava compreender como os alunos entendem o equilíbrio químico.

Considere o seguinte sistema em equilíbrio:

$\mathrm{N}_{2}(\mathrm{~g})+3 \mathrm{H}_{2}(\mathrm{~g}) \rightarrow 2 \mathrm{NH}_{3}(\mathrm{~g})$

A aplicação de uma pressão crescente, apenas no lado esquerdo, fará com que o equilíbrio se desloque para a direita. Esta afirmação a) está correta.

b) não está correta. O equilíbrio se deslocará para a esquerda.

c) descreve ação impraticável.

d) está correta se a amônia for continuamente removida.

\section{Justifique.}

Para as turmas dos anos de 2003 e 2004, respectivamente, os índices de erro gerais foram de 74 e $82 \%$. A impossibilidade física da aplicação de pressão a apenas alguns dos componentes do sistema em equilíbrio foi reconhecida por uma minoria dos alunos. Cerca de $60 \%$ do total, respondeu que um aumento de pressão "do lado dos reagentes" desloca o equilíbrio no sentido de formação dos produtos, invariavelmente.

"correta: O aumento da pressão desloca o equilíbrio no sentido da formação de compostos que ocupam menor volume." (prova 1)

"Está correta pois o aumento da pressão num sistema gasoso, faz com que aumente o $n^{o}$ de colisões efetivas." (prova 11)

"A afirmação segue o princípio de Le Chatelier. Obs. O deslocamento seria acentuado se a amônia fosse continuamente removida, como no processo Haber." (prova 26)

"Não está correta. Com o aumento da pressão, a temperatura também aumentará, e o equilíbrio se deslocará para a esquerda." (prova 84)

"Está correta, pois segundo o princípio de Le Chatelier, quando aumentamos a pressão em um determinado sistema, este tende a se deslocar no sentido que diminui o número de mols de gás. Portanto, o equilíbrio desloca-se para a direita porque possui menos mols de gás (2 mols) que a esquerda (4 mols)." (prova 95)

"A amônia deve ser continuamente removida, pois caso contrário as pressões no lado esquerdo e direito tende a igualar-se, o que trará o equilíbrio novamente, apesar de estarem em quantidades diferentes do que no sistema inicial." (prova 100)

Essa foi também uma questão que revelou problemas generalizados nos ingressantes. Os índices de erro foram superiores a $67 \%$ em todas as condições e chegaram a $100 \%$ em duas das turmas investigadas.

Análise dos problemas encontrados nas respostas às questões das provas de 2003 a 2006 nos diferentes cursos

Dos problemas encontrados nas respostas às questões, dois se destacam pela sua frequiência elevada nos diferentes cursos e em todos os anos analisados (Tabela 1). Um deles refere-se à mecanização do algoritmo da reação de "dupla troca", o que pode significar que esses estudantes ingressam no IQ-USP sem um reconhecimento da presença de íons em solução e de como ocorre a dinâmica das reações em fase aquosa. A representação da equação química parece estar induzindo a construção de um modelo equivocado em que os íons simplesmente não são formados.

O outro problema encontrado com maior freqüência foi a mecanização do Príncípio de Le Chatelier nos equilíbrios químicos. Aqui também, um modelo que pode ser inferido pelas respostas expressas é que existe uma "força" que "desloca" reagentes até os produtos e vice-versa, e a reação aconteceria como se as espécies químicas estivessem em ambientes separados. Parece-nos também que esse modelo deve estar sendo induzido pela representação da equação química, onde os reagentes e produtos são "separados" pelas setas representativas do equilíbrio. $\mathrm{O}$ modelo que pode ser inferido através da nossa interpretação a partir das respostas dos estudantes é o representado na Figura 6, onde a reação aconteceria com reagentes e produtos situados em compartimentos separados e as espécies em solução estariam em forma de "pares iônicos".

\section{CONSIDERAÇÕES FINAIS}

Um instrumento diagnóstico foi desenvolvido para avaliar as concepções de química trazidas do Ensino Médio pelos estudantes 


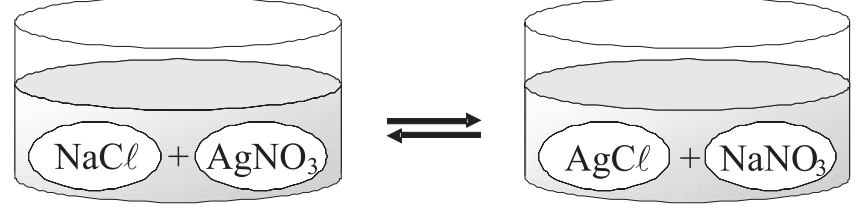

Figura 6. Modelo de reação química interpretado pelos autores a partir das respostas expressas dos alunos

ingressantes nos três cursos de graduação do IQ-USP. A Verificação de Conhecimentos buscou diagnosticar problemas relacionados à compreensão de conceitos químicos considerados fundamentais para o futuro químico.

Os resultados obtidos pelos estudantes nessa avaliação refletem, em parte, os diferentes perfis entre os estudantes que buscam a sua formação como licenciado, como químico ambiental ou como bacharel em química. No geral, o desempenho médio dos alunos do Bacharelado é mais favorável do que aquele dos alunos da química Ambiental e Licenciatura, o que correlaciona com as notas de corte e a relação candidato/vaga no vestibular.

Por outro lado, um diagnóstico mais refinado pode ser obtido a partir da comparação do desempenho individual de cada aluno em duas avaliações: a segunda fase de química da Fuvest e a Verificação de Conhecimentos. Quando se procura correlacionar linearmente o desempenho dos estudantes nessas duas avaliações, observa-se um valor baixo do coeficiente de correlação $(r=0,65)$, que pode ser atribuído a uma diferença nos objetivos das duas provas. Esse resultado nos mostra que, para o propósito de identificar as concepções dos ingressantes do IQ-USP, não podemos ter por base exclusivamente a avaliação da Fuvest, ou seja, a prova de Verificação de Conhecimentos é útil por fornecer outras informações relevantes para a Instituição.

Ao se analisarem os tipos de erros cometidos nas questões da avaliação, percebe-se uma relativa homogeneidade entre os estudantes. As dificuldades diagnosticadas incluem: a extrapolação de propriedades macroscópicas da matéria para átomos isolados; modelos equivocados sobre mudanças de estado; dificuldades em compreender a natureza corpuscular da matéria; problemas com a compreensão da dissociação iônica; explicações equivocadas e mecânicas para justificar a força de ácidos; incompreensão do conceito de equilíbrio químico e, dificuldades na resolução de problemas não familiares.

Dentre os problemas detectados, dois se destacam pela sua alta incidência: o uso dos algoritmos da reação de "dupla troca" e do Príncípio de Le Chatelier. No primeiro caso, os estudantes recorrem ao algoritmo da "dupla troca" por não levarem em consideração o processo de dissociação iônica. No segundo caso, se revela uma dificuldade na compreensão da coexistência de reagentes e produtos no meio reacional. Em ambos os casos, portanto, transparece uma compreensão inadequada da equação química: pela ausência da representação iônica e pela separação feita pela seta de equilíbrio entre reagentes e produtos. Esses resultados revelam uma dificuldade no que se refere à linguagem química, induzindo a modelos alternativos de reação química em solução aquosa, a qual ocorreria, segundo os modelos expressos pelos estudantes, entre "pares iônicos" e/ou entre compartimentos separados. A partir desses modelos, podemos inferir que a maior dificuldade aqui apresentada refere-se à linguagem química. A equação química necessita de uma mediação do professor para ser compreendida pelos estudantes, pois o entendimento que o químico possui da mesma não é óbvio para os estudantes. Os símbolos na equação precisam ser "traduzidos" passo a passo, de modo a promover uma aproximação gradual de significados.

Tendo em mente esses problemas e os modelos equivocados das reações químicas, vale um alerta aos docentes que ministram disciplinas introdutórias, para que planejem atividades em sala de aula de modo a poder observar se esses modelos são expressos pelos estudantes e assim tentar promover uma mudança nos mesmos antes de passarem a desenvolver novos conceitos. De outro modo, os novos conceitos serão ancorados numa estrutura possivelmente equivocada, e passarão assim a ser utilizados pelo estudante para a construção de novos modelos não condizentes com os aceitos cientificamente.

Por fim, o compromisso da Universidade é com a formação de profissionais preparados para enfrentar o mercado de trabalho, com habilidades e competências de resolução de problemas e com uma visão crítica dos fenômenos. Nesse sentido, a informação obtida através da análise das respostas às questões nessa prova é complementar àquela obtida pelo vestibular, e mostra que os alunos ingressantes no IQ-USP apresentam problemas com conceitos químicos que podem ter advindo de uma formação educativa onde o que tem contado é a devolução de fatos. A iniciativa da avaliação de Verificação de Conhecimentos é, portanto, um passo importante na direção de tentar corrigir anos de reprodução de fatos e caminhar na direção da construção de conceitos.

\section{AGRADECIMENTOS}

Aos docentes do Instituto de Química que elaboraram as questões da Verificação de Conhecimentos e aos alunos ingressantes que participaram dessa investigação.

\section{REFERÊNCIAS}

1. de Andrade, J. B.; Pinto, A. C.; Cadore, S.; Vieira, P. C.; Zucco, C.; Pardini, V. L.; Curi, L. R. L.; Quim. Nova 2005, 28 Suplemento, S7.

2. de Andrade, J. B.; Cadore, S.; Vieira, P. C.; Zucco, C.; Pinto, A. C.; Quim. Nova 2003, 26, 445.

3. de Andrade, J. B.; Cadore, S.; Vieira, P. C.; Zucco, C.; Pinto, A. C.; Quim. Nova 2004, 27, 358.

4. Zucco, C.; Quim. Nova 2005, 28 Suplemento, S11.

5. PISA, Program for International Student Assessment, coord. OECD Organization for Economic Co-operation and Development, 2003; http:// www.oecd.org/document/62/0,2340,en_32252351_32236159_3457555 0_1_1_1_1,00.html, acessada em Dezembro 2006.

6. Brasil, Ministério da Educação. Censo Escolar - Instituto Nacional de Estudos e Pesquisas Educacionais Anísio Teixeira, 2005; http://www. inep.gov.br/basica/censo/dados.asp, acessada em Novembro 2006.

7. Wagner, E. P.; Sasser, H.; DiBiase, W. J.; J. Chem. Educ. 2002, 79, 749.

8. Bentley, A. B.; Gellene, G.. I.; J. Chem. Educ. 2005, 82, 125.

9. Tsaparlis, G.; Zoller, U.; U. Chem. Ed. 2003, 7, 50.

10. Zoller, U.; Dori, Y.; Lubesky, A.; Int. J. Sci. Educ. 2002, 24, 185; Lipman, M. O.; Pensar na Educação, Vozes: Petrópolis, 2003.

11. Taber, K. S.; University Chemistry Education 2000, 4, 63.; Taber, K. S.; Chemistry Education: Research and Practice in Europe 2001, 2, 43.

12. Fernandez, C.; Marcondes, M. E. R.; Química Nova na Escola 2006, n²4, 20; Harrison, A. G.; Treagust, D. F.; Sci. Educ. 1996, 80, 509; Garnett, P. J.; Hackling, M. W.; Studies in Science Education 1995, 25, 69; Mulford, D. R.; Robinson, W. R.; J. Chem. Educ. 2002, 39, 797; Ebenezer, J. V.; Erickson, G. L.; Sci. Educ. 1996, 80, 181; P1narbasi, T.; Canpolat, N.; J. Chem. Educ. 2003, 80, 1328; Kabapinar, F.; Leach, J.; Scott, P.; Int. J. Sci. Educ. 2004, 26, 635; Griffiths, A. K.; Preston, K. P.; J. Res. Sci. Teach. 1992, 29, 611; Peterson, R. F.; Treagust D. F.; Garnett, P.; J. Res. Sci. Teach. 1989, 26, 301; Pedrosa M. A.; Dias, M. H.; Chemistry Education Research and Practice 2000, 1, 227; Barker, V.; Millar, R.; Int. J. Sci. Educ. 2000, 21, 645; Boo, H. K.; J. Res. Sci. Teach. 1998, 35, 569.

13. Ben-Zvi, R.; Eylon, B.; Silberstein, J.; J. Chem. Educ. 1986, 63, 64; Mortimer, E. F.; Química Nova na Escola 1995, nº1, 23.; Mortimer, E. 
F.; Miranda, L. C.; Química Nova na Escola 1995, n², 23; Rosa, M. I. F. P. S.; Schnetzler, R. P.; Química Nova na Escola 1998, nº8, 31.

14. Osborne, R. J.; Cosgrove, M. M.; J. Res. Sci. Teach. 1983, 20, 825.

15. Tyson, L.; Treagust, D. F.; J. Chem. Educ. 1999, 76, 554; Banerjee, A. C.; Int. J. Sci. Educ. 1991, 13, 487; Machado, A. H.; Aragão, R. M. R.; Química Nova na Escola 1996, nº 48.
16. Smith, K. J.; Metz, P. A.; J. Chem. Educ. 1996, 73, 233.

17. Treagust, D. F.; Int. J. Sci. Edu. 1988, 10, 159.

18. Nery, A. L. P.; Liegel, R. M.; Fernandez, C.; Química Nova na Escola 2006, n'23, 14. 